\title{
Estimate of depths of source fluids related to mound fields on Mars
}

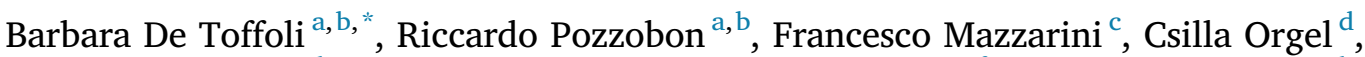 \\ Matteo Massironi ${ }^{\mathrm{a}, \mathrm{b}}$, Lorenza Giacomini ${ }^{\mathrm{e}}$, Nicolas Mangold ${ }^{\mathrm{f}}$, Gabriele Cremonese ${ }^{\mathrm{b}}$ \\ ${ }^{a}$ Department of Geosciences, University of Padova, Via Gradenigo 6, Padova 35131, Italy \\ ${ }^{\mathrm{b}}$ INAF, Osservatorio Astronomico di Padova, Vicolo dell'Osservatorio 3, Padova I-35122, Italy \\ ${ }^{\mathrm{c}}$ Istituto Nazionale di Geofisica e Vulcanologia, Via Della Faggiola 32, Pisa 56100, Italy \\ ${ }^{\mathrm{d}}$ Institute of Geological Sciences, Planetary Sciences and Remote Sensing, Freie Universität, Berlin, Germany \\ ${ }^{\mathrm{e}}$ INAF, Istituto di Astrofisica e Planetologia Spaziali, via Fosso del Cavaliere 100, Roma 00133, Italy \\ ${ }^{\mathrm{f}}$ Laboratoire de Planétologie et Géodynamique, Université de Nantes, Nantes, France
}

\section{A R T I C L E I N F O}

\section{Keywords:}

Fluid circulation

Mars

Fracture systems

Mounds

\begin{abstract}
A B S T R A C T
The investigation of the Martian surface through remote sensing allowed the identification of mound-like topographically positive features that, based on geomorphological observations, have been ascribed to different phenomena. New observations will be performed in the forthcoming future to look for possible methane sources, hence discriminating morphologically similar features is a key objective to efficiently investigate and target the Martian surface. Here, we performed fractal analysis on five Martian fields of mound-like features that have been interpreted respectively as mud volcanoes, pingos, tumuli, rootless cones and monogenetic volcanic vents successfully validating the major interpretations of these features and in turn, the applicability of the fractal clustering method for discriminating among such features. Indeed, this technique is able to assess if the analyzed features are directly related to underlying systems of connected percolating fracture networks and estimates their extension in the subsurface. Accordingly, volcanic vents and mud volcanoes appeared to be connected to percolating systems involving several kilometers of crust, pingos and tumuli resulted to be unequivocally unrelated to active percolating fractures while rootless cones outputted weak relationship with shallow active fracture systems.
\end{abstract}

\section{Introduction}

The analysis of the spatial clustering of vents and/or fractures, on rocky and icy planetary surfaces, can provide information about the fracture network exploited by fluids during their flow up and their linkage with the possible fluid source at depth. In particular, the analysis of the self similar (fractal) clustering, either applies to fractures themselves or to eruption vents, has been already used to explore the fluid source depth and the crust mechanical layering on Earth, Mars and Enceladus (Mazzarini, 2004; Mazzarini \& Isola, 2010; Le Corvec et al., 2013; Pozzobon et al., 2015, Lucchetti et al., 2017). Thus, besides the investigation of fractures (e.g. Renshaw, 1999; Bonnet et al., 2001; Mazzarini \& Isola, 2010), this method has been recognized as a valid technique to be applied to features that have a well-known relationship with subsurface flows of materials providing insights on the application of the method to estimate the depths of the reservoirs, such as volcanic vents (Mazzarini, 2004; Mazzarini \& Isola, 2010), mud volcanoes (Bonini
\& Mazzarini, 2010) and on volcanic dykes on Mars (Pozzobon et al., 2015).

In this work we test the reliability of this technique for discriminating mound features on Mars apt to be confused due to their morphological similarities. Accordingly, we have applied the fractal methodology on case studies where there is wide consensus on the interpretation of the morphologies. Our work is therefore focused on providing an innovative tool to distinguish features related to near-surface vs. deep-rooted phenomena and additionally provide a more solid interpretation. Specifically, herein are considered: monogenic volcanic vents, mud volcanoes, pingos, rootless cones and tumuli (Hargitai and Kereszturi, 2015). Indeed, all of these morphologies during their evolution stages can come to appear as mounds, organized within large fields, and, undergoing a cross comparison process with terrestrial analogue features, uncertainties arise due to the presence of characteristics that can lead to more than just one interpretation. The technique presented in this work provides information on the occurrence of a deep-rooted pathway hydraulically

\footnotetext{
* Corresponding author. via G.Gradenigo 6, 35131 Padova, Italy.

E-mail addresses: barbara.detoffoli@gmail.com, barbara.detoffoli.1@phd.unipd.it (B. De Toffoli).
} 
connecting the surface to deep reservoir systems. Therefore, it can be used to distinguish between formation mechanisms that are related or unrelated to connected fracture networks, providing also estimates about the fluid source depths when the connectivity exists, so leading to a discrimination of different types of resurgence products and mechanisms.

\section{Background}

To address the objective of providing a new tool unbiased by geomorphological observations to help the discrimination of mound-like morphologically convergent features, we herein undertook the analyses only on samples of structures which interpretation has been well accepted among the scientific community so to leave the focus on the efficiency of the method.

Specifically, volcanic vents, mud volcanoes, pingos, rootless cones and tumuli will be under examination since all of them can appear as mound-like topographically positive features and all of them have been observed on the Martian surface (Fig. 1; Fig. 2; Fig. 3 and references therein).

The comparative process of investigation between well-known regions, in this case on Earth, and the ones under examination on Mars is crucial and leads to a better understanding of objects on both sides. In this work frame, we concurrently addressed some terrestrial analogue features to investigate more deeply those categories that have never undergone fractal analysis before, that is to say rootless cones, tumuli and pingos. The methodology herein discussed is indeed meant to provide information about fracture-related phenomena, thus allowing the user to tell apart processes that involve widely different crustal thicknesses. Accordingly, in the past, it has been applied only where fracture systems where already known to underlie the surface structures (e.g. Bonini and Mazzarini, 2010; Mazzarini and Isola, 2007, 2010) leaving unexplored very shallow process expressions. Thus, we selected one terrestrial analogue region for each unexplored feature category choosing areas where fields large enough are recognizable through the observation of satellite images. The analyses described in the following sections were carried out on both planets by performing manual mapping of edifices and accordingly applying fractal analysis. Although we performed consistent and comparable procedures, throughout the mapping process terrestrial and Martian environments showed different limitations. On Mars an easier identification of mound fields is facilitated by a wide continuous coverage of the surface by mid-resolution (MRO CTX, $\sim 6 \mathrm{~m}$ /pixel) images and due to favorable environmental conditions, i.e. absence of disturbance factors such as vegetation covering or clouds. On Earth, remote observation of the surface faces stricter limits such as smaller dimensions of features, because of gravity difference in comparison to Mars, vegetation covering and/or more intense weathering degradation. Terrestrial analogues are sites showing geological and environmental conditions resembling the ones that characterize locations of interest on Mars; although this allows to collect a broader amount of information, differences mainly driven by gravity occur. On Mars gravity is around one third $\left(3711 \mathrm{~m} / \mathrm{s}^{2}\right)$ of Earth's counterpart and this substantially affects morphologies and dimensions of features, particularly when considering resurgence processes. In fact, lower gravity impacts material traits such density and compaction, leading fluid masses to more easily rise buoyantly when less dense than the surrounding rock, and it affects volumes involved in resurgence processes as well, that end up being larger since more mass is needed to crack the host medium and let the buoyant materials rise; accordingly, to accommodate such increased volumes, thicknesses of lithosphere wider than their terrestrial counterpart may be involved (e.g. Carr, 2006). We herein chose to analyze shallow-processes terrestrial features which identification and interpretation is already assessed and accepted among the scientific community so to leave, once more, the focus on the efficiency of the method. On this base, we considered the following terrestrial locations (Fig. 2): (i) 1783-84 Laki lava flow in Iceland for rootless cones (Hamilton et al., 2010; Bruno et al., 2006); (ii) Llancanelo Volcanic Field, Mendoza,
Argentina for tumuli (Nemeth et al., 2008); (iii) Kolyma Lowland, North Asia for pingos (Grosse and Jones, 2011).

Overall, all the investigated features on Mars and on Earth, although similar in shape, may result from significantly different processes as the upwelling of materials and fluids from beneath, (with varying thickness of medium and natures of the extruded materials) or from thermomechanical processes (Fig. 3). By the application of fractal analysis, we hence aim to provide insights about the possible presence of connectivity between mounds and fractures and so distinguishing between fracturerelated or fracture-unrelated processes, thus integrating and strengthening the information datasets that concur to the interpretation of mound-like features, particularly where actual connection with percolating systems occur and further details about the fluid source depths can be inferred.

\subsection{Monogenetic volcanic vents}

Monogenetic vents are volcanoes that, according to several authors (e.g. Smith and Nemeth, 2017; Nemeth and Kereszturi, 2015; Nemeth, 2010; Connor and Conway, 2000) are the product of single episodes short lived, small-volume and normally deep-sourced, hence mafic, volcanic activity. They are associated to feeder dykes fed from deep sources siting at several tens of kilometers in the subsurface and have no real associated to shallower magma chambers. The feeding systems of monogenetic vents are connected to magmatic reservoirs sited at depth within the lithosphere. We herein analyzed the monogenetic volcanic vents located in the Tharsis region (Pavonis Mons South and South-Eastern Volcanic Fields) described and mapped by Bleacher et al. (2009) and (2007a).

\subsection{Mud volcanoes}

Mud volcanoes are the result of upflows of gases, water and sediments from the subsurface that occur when the buoyancy forces that push the mixtures exceed the confining lithostatic pressure (van Loon, 2010; Kopf, 2002). The rapid sedimentation and low permeability of surrounding strata can lead to store undercompacted levels at depth and therefore overpressured and buoyant. The resurgence can be triggered by new fluid supply, increasing of pore pressures and a decrease of viscosity that could be produced by various events such as tectonic loading, impact cratering unloading, hydrothermal pulses, hydrocarbon generation, or injection of gas through dissociation of clathrates (Dimitrov, 2002; Kopf, 2002; Prieto-Ballestreros et al., 2006; Skinner and Tanaka, 2007; Skinner and Mazzini, 2009; Oehler and Allen, 2010 and references therein). Mud volcanoes are topographically positive features that can come in single or coalescent mounds, dome or pie shaped (depending on the flattening grade estimated on slope angles, specifically the term mud pie is usually applied when less that $5^{\circ}$ (e.g. Kopf, 2002; Mazzini and Etiope, 2017)). This phenomenon has been herein addressed by mapping and investigating a sample of Acidalia Planitia cones interpreted as mud volcanoes (e.g. Oehler and Etiope, 2017; Oehler and Allen, 2010). Thousands of mud volcanoes have been observed in that area, showing the typical mud volcano dome shape, circular base, light albedo, low thermal inertia, central pit and flow features (Oehler and Allen, 2010, 2012).

\subsection{Pingos}

Pingos are periglacial landforms produced by the upwelling of freezing water that results in transient hill shaped morphologies. Such appearance is, indeed, due to the volume increase during the transition from liquid water, capillary up-flowing, to solid state ice close to the surface and are usually subjected to apex collapse due to the subaerial exposition and destabilization of the ice core. Pingos go through different evolution stages that affect their morphology. They firstly appear like surface bulges with no summit depressions; later, during the growth process, the surface dissects leading to the beginning of the mound collapse, thus orthogonal, tensional single or multiple intersecting cracks 

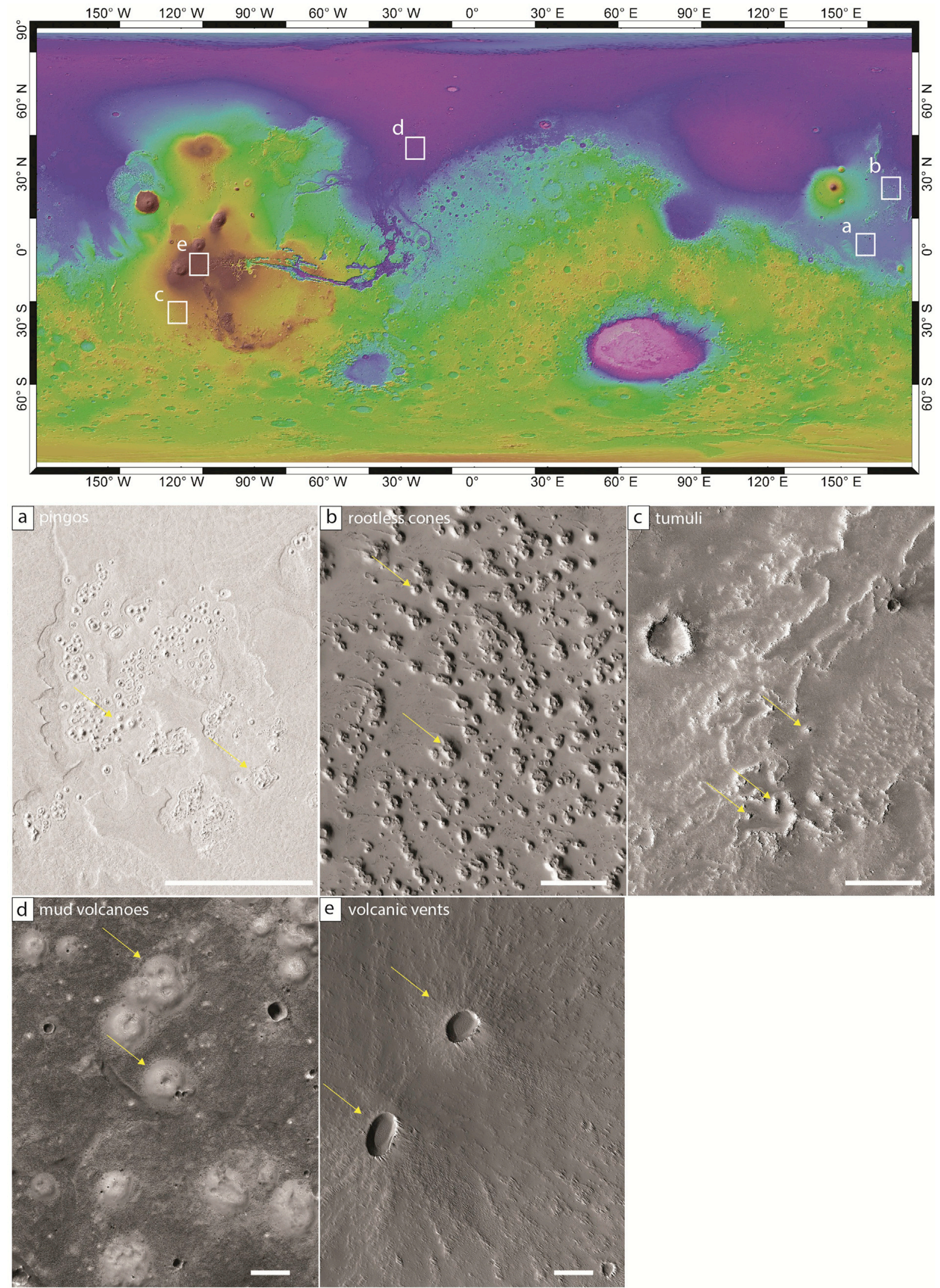

Fig. 1. On the map, locations of the study areas are indicated by white boxes. Samples of features interpreted as a) pingos (PSP_009280_1905) in Athabasca Valles (Balme and Gallagher, 2009), b) rootless cones (ESP_047085_2060) in Phlegra Dorsa region (Bruno et al., 2004), c) tumuli (PSP_002711_1550) in Daedalia Planum (Giacomini et al., 2009), d) mud volcanoes (PSP_008522_2210) in Acidalia Planitia (Oehler and Allen, 2010) and d) monogenetic volcanic vents (ESP_014037_1760) in the Tharsis Province (Bleacher et al., 2009). Arrows highlight single and, where present, coalescent structures of each object type. (scale bars: $500 \mathrm{~m}$ ). 

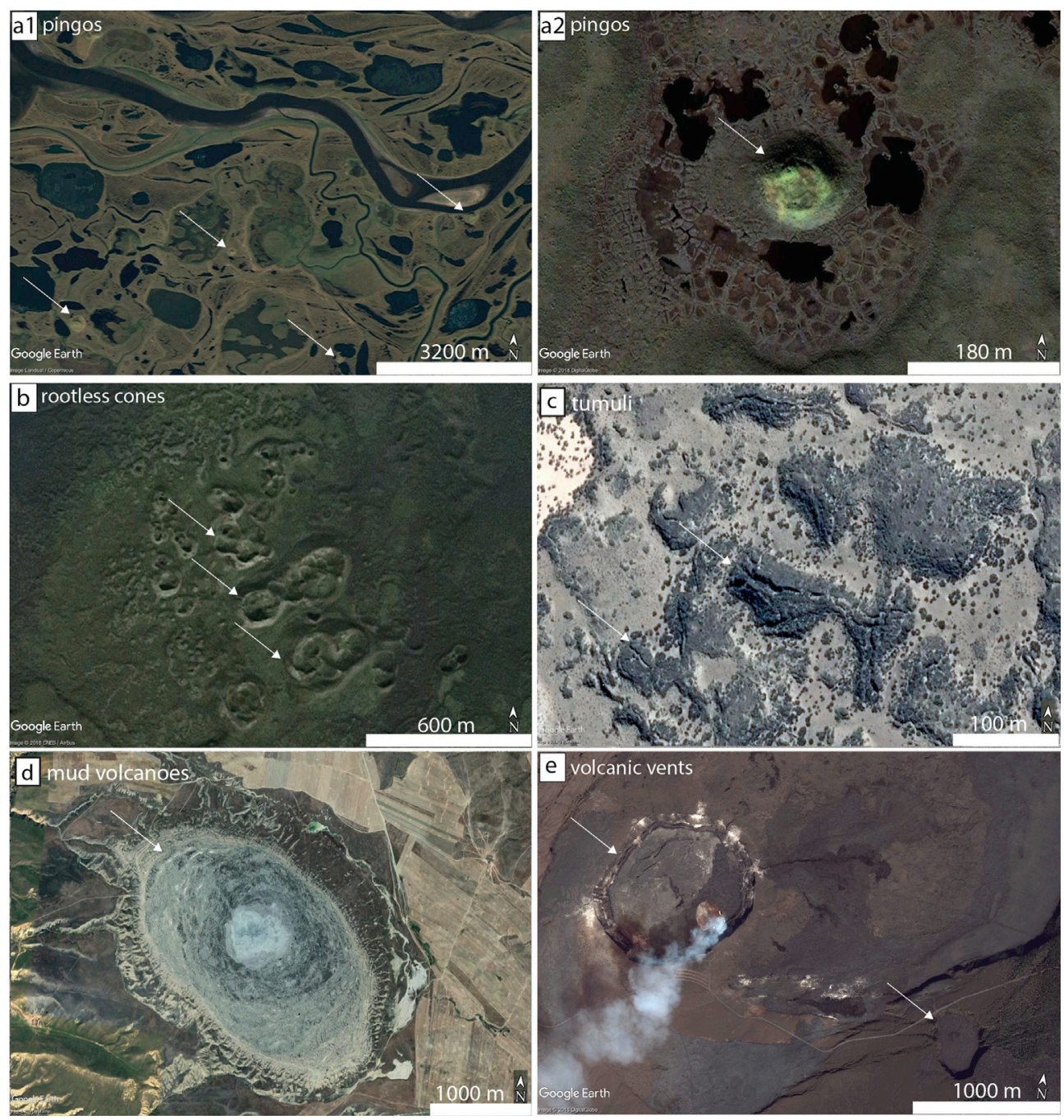

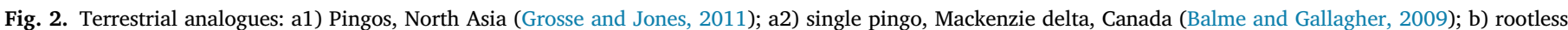

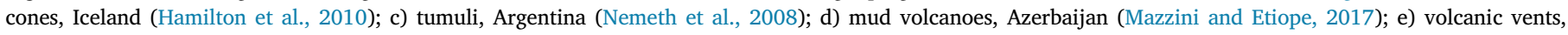
Kilauea, Hawaii.

propagate downslope from their tops; after the melting process, the remnants of pingos appear like shallow, rimmed depressions whose margins can merge forming overlapping, lobate, irregular features (e.g. Page and Murray, 2006; Burr et al., 2009; Dundas and McEwen, 2010). As case study, we mapped a group of features interpreted as pingos in Athabasca Valles from their shape and localization inside a flood valley (Page and Murray, 2006; Balme and Gallagher, 2009).

\subsection{Rootless cones}

Rootless cones (or pseudocraters) are volcanic exit points of pyroclasts derived from an explosive interplay, produced for instance by the interaction between volatile-rich substrates and lava flows (Thorarisson, 1953), and are characterized by a lack of vertical magmatic feeder networks (Bruno et al., 2004; Sheth et al., 2004; Lanagan et al., 2001; Keszthelyi and Self, 1998). The definition of "rootless" lays in the absence of magma chambers feeding the cones. These can come in single, double or multiple concentric and/or coalescent cones with steep sides and summit crater (Noguchi et al., 2016). Distribution of rootless cones on the surface can be clustered, but their non-random arrangement is ascribed to lava pathways (Bruno et al., 2004). We addressed rootless cones investigation by mapping a portion of a rootless cone field in the Phlegra Dorsa region from their localization at the edge of lava flows (e.g.
Bruno et al., 2006; Lanagan et al., 2001).

\subsection{Tumuli}

Tumuli are circular to elliptical knobby positive features displaying clefts on the top that are produced on lava flows' surface due to magmatic overpressure which can locally induce uplift on the sealing crust (Nemeth et al., 2008, 2017; Mattsson and Hoskuldsson, 2005; Rossi and Gudmundsson, 1996; Walker, 1991; Ollier, 1964). In fact, the movement of inflated lava is initially distributed uniformly throughout the liquid core and then, progressively, differential cooling occurs focusing lava flux. At this stage, when obstacles are encountered by the lava flow a localized inflation may create tumuli (Hon et al., 1994). Alignments can be observed also in tumuli distribution due to preferential magma pathways, such as lava tubes, within the inflation (Giacomini et al., 2009). A knob field located in Daedalia Planum, already ascribed to tumuli uplift process, has been herein addressed as a case study for this category (Giacomini et al., 2009; Giacomini and Massironi, 2010). In this specific case, the recognized tumuli are mounds with mainly elliptical shape and are placed on basaltic lava flows spreading on the southwestern flank of Arsia Mons. Some of these have radial or axial cracks on their top, however most of the tumuli lack well-preserved clefts, rather showing a rough surface covered in boulders (Giacomini et al., 2009). 


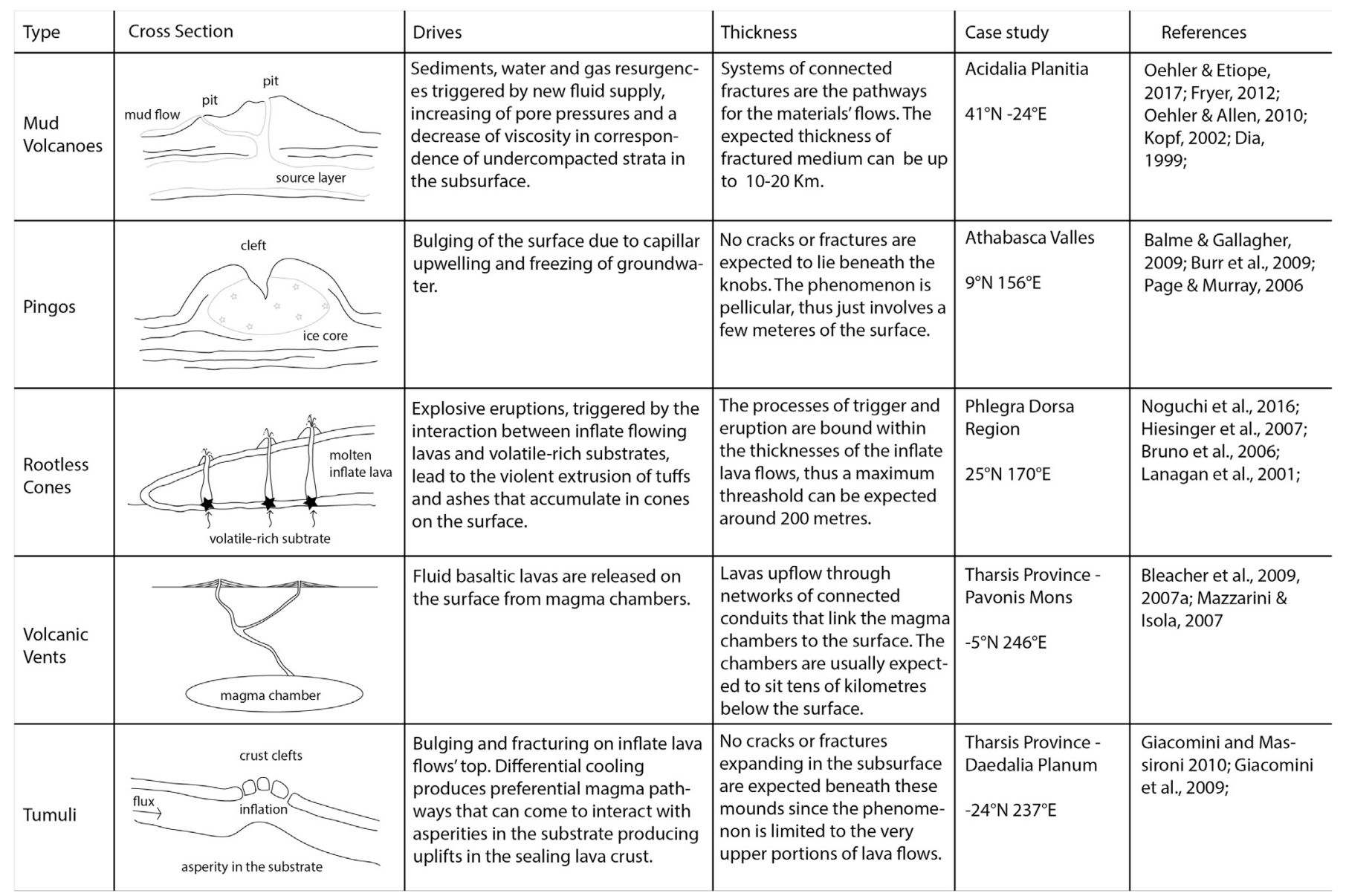

Fig. 3. Specific traits are listed and sketched for each feature class highlighting the wide variety of interplays with the subsurface that these surface expressions have despite the morphological analogy.

\section{Methods}

We mapped the features of interest and performed the self-similar clustering (i.e. fractal) analyses to produce comparable datasets to appreciate how the surface distribution of mounds express the eventual association with hydraulically connected fracture systems extending in the subsurface. Each feature was distinguished from the neighboring through manual identification. This mapping procedure were carried out using (i) Context Camera (on board Mars Reconnaissance Orbiter) images (Malin et al., 2007), or mosaics where necessary (produced by means of Pilot software; pilot.wr.usgs.gov), which has a resolution data capture of $6 \mathrm{~m} /$ pixel and provide a total coverage of the areas, and (ii) HiRISE (High Resolution Imaging Science Experiment on board the Mars Reconnaissance Orbiter mission) images to enhance the observation, when available (McEwan et al., 2007).

Where a large number of features were mapped (i.e. rootless cones), clustering of mounds was performed computing the coordinates of all the vents in MINITAB ${ }^{\circledR}$ software and applying an agglomerative hierarchical clustering method (Mazzarini, 2007). This approach is used when the number of clusters is initially unknown. The optimal number of clusters is derived by analyzing the dendrogram that depicts the amalgamation of observations into one cluster. The similarity at any step is defined, in this case, by the maximum distance between points. Where the step values change abruptly, the dendrogram may be cut and accordingly the best suitable number of clusters can be inferred (Mazzarini, 2007). The coordinates used for the analysis were extrapolated by sinusoidal projections of the surface of Mars centered on the observed area, for this reason the procedure was separately repeated for each area. Then for each defined cluster the self-similar cluster analysis has been performed.
Fractal analysis is a methodology that, starting from the observation of fractures or vents, allows to infer the extension of the connected fracture network actually draining the fluids from the deep source toward the surface. In fact, fractures' length and their spatial distribution control the overall permeability of fracture networks (e.g. Darcel et al., 2003). The percolation theory quantifies a critical fracture density threshold that defines the limit above which the fracture network is connected (Mazzarini and Isola, 2010 and references therein). When the fracture network is actually percolating its spatial distribution is fractal and its self-similarity is defined in a specific lengths range bounded by a lower and an upper cutoff (e.g. Mandelbrot, 1982). Such analysis evaluates the scaling properties of the systems and, in particular, the derived upper cutoff is assumed to represent the distance between the surface and the fluid source at depth (e.g. Mazzarini and Isola, 2010).

We performed self-similar clustering (i.e. how the features fill the space; Fig. 4) of the datasets of interest by applying the following scaling equation:

$C(l) \cdot \alpha \cdot l^{-D}$

where $C(l)$ is the correlation sum, defined as $C(l)=2 \mathrm{~N}(l) / N(N-1)$ where $N(l)$ are the pairs of points whose distance is less than $l$, and $D$ is the fractal exponent. The $D$ exponent is defined as the slope of the tangent to the $\log (C(l))$ vs. $\log (l)$ curve (equation (1)); high $D$ values imply increasingly homogeneous distribution of fractures, low values imply increasingly clustered distribution of fractures (Darcel et al., 2003 Mazzarini and Isola, 2010).

The fractal distribution can be inferred from the analysis of a $\log (C(l))$ v. $\log (l)$ diagram (Bonnet et al., 2001). Since the upper cutoff (Uco) scales 


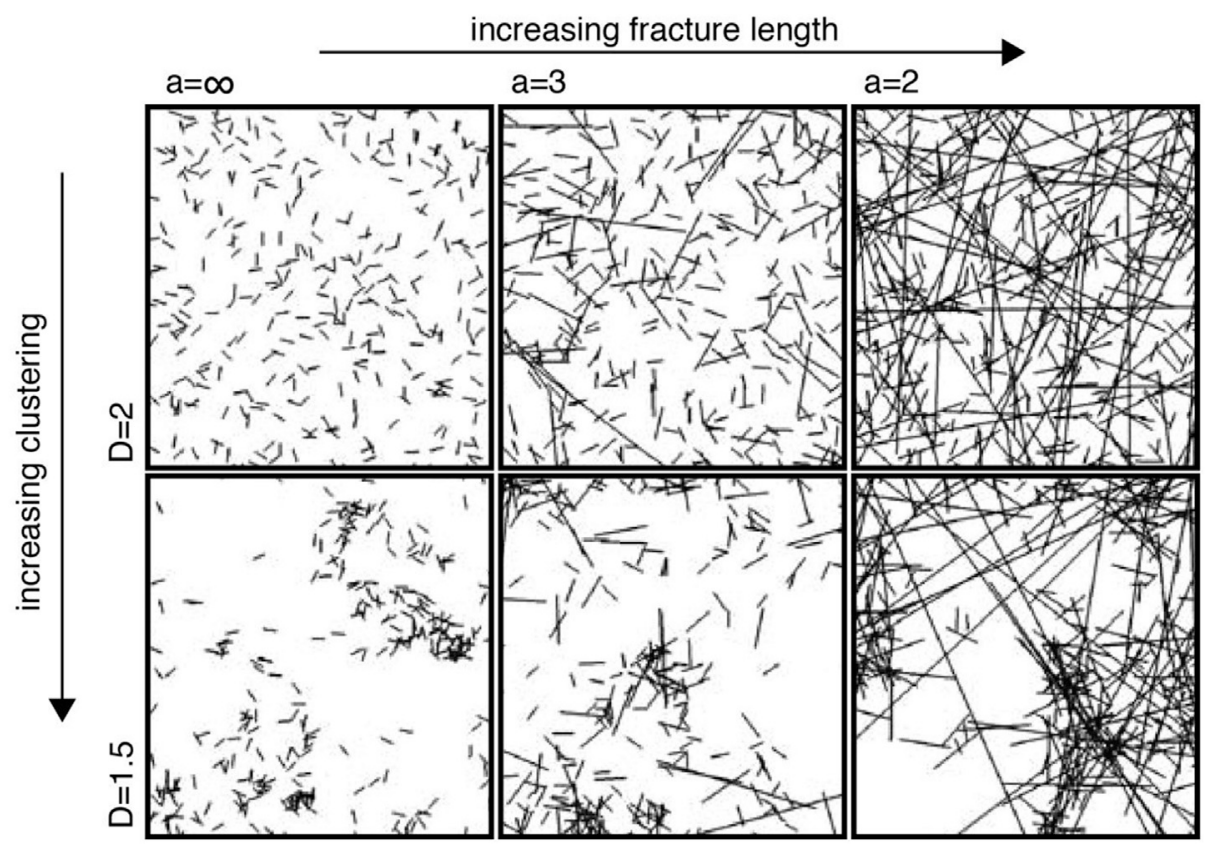

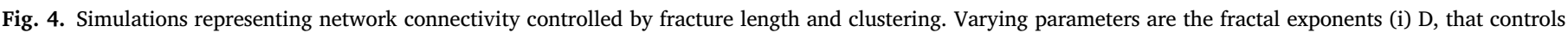

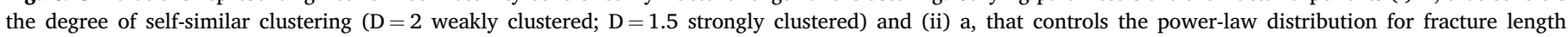
(increasing lengths from $\mathrm{a}=\infty$-short- to $\mathrm{a}=2$-long-). Adapted from Darcel et al. (2003) and Mazzarini and Isola, 2010.

as the maximum thickness of the fractured medium, this is the specific parameter to investigate in order to shed light on the extension of the phenomenon and thus on possible fracturing processes (e.g. wide plumbing system, shallow fracturing, overpressure fracturing, etc.; Mazzarini and Isola, 2010 and references therein). The size range, bound within the lower and upper cutoffs, is detectable as a linear fit (a plateau) in a local slope $\Delta \log (C(l) / \Delta \log (l)$ ) vs. $\log (l)$ diagram (Fig. 5 a-1; Walsh and Watterson, 1993). Thus, the Uco (upper cutoff; i.e. the highest plateau breaking point) is defined by the maximum value of the size range, which is the maximum extension of the pipeline connecting the reservoirs to the surface, thus it represents the depth of the fluids source (Mazzarini and Isola, 2010 and references therein). The goodness of the Uco picking was estimated on the basis of the maximum values of the coefficient $R^{2}$ defined as the proportion of data variability in cutoffs' interval. $R^{2}$ is defined as shown in equation (2)

$R^{2}=1-\frac{S S_{\text {res }}}{S S_{\text {tot }}}$

where $S S_{\text {res }}$ represents the residuals sum of squares, which is meant to be minimized in proportion to the normalization coefficient $S S_{\text {tot }}$ (total sum of squares) in accordance to the order of magnitude involved in the calculation. We detected the depth range corresponding to the higher values of $\mathrm{R}^{2}$, thus describing the values of best-fit for the Upper cutoff. The error of the measure was estimated calculating the half-difference between the maximum and the minimum Uco's values depths where the $\mathrm{R}^{2}$ shows the best-fit value providing to ensure the largest size range. To make the analysis more robust, we also produced a cross check among the $\Delta \log (C(l) / \Delta \log (l))$ vs. $\log (l)$ diagrams (where the eventual fractal behavior is displayed by a plateau) and plots of all possible $\Delta \log (l)$ (i.e. size range) and $\mathrm{R}^{2}$ values. In this second diagram, a significant break in the slope should be detected when fractal clustering occurs and, the higher the $\mathrm{R}^{2}$ value is in correspondence of the breaking point, the higher is the reliability of the information. Hence this additional analysis tests the reliability of the Lco-Uco extension estimate giving a graphic quantitative measure of the reliability of the cutoffs picking (Fig. 5).

Therefore, if no plateau is recognizable in the diagram, the examined features have no fractal behavior and, therefore, no relationship with system of connected fractures at depth. In order to produce meaningful estimates, the sample size effect needed to be taken into account. As a rule of thumb, at least 50 samples are required to extract robust parameter estimates (Clauset et al., 2009) and, accordingly, in our study the number of observed mounds spans between a minimum of 65 to a maximum of 1428 per single cluster (Table 1 ).

Indeed, this large number of observations endure a robust estimate of the fractal distribution parameters. In particular, Mazzarini and Isola (2010) showed that removing a random sample of $20 \%$ of the vents from large (i.e. $>200$ vents) datasets does not affect the estimation of the fractal exponent (less than $0.01 \%$ of variation) and the error introduced into the estimation of the cut-offs is less than 1\%-2\%. In Mazzarini et al. (2013) the effect of uncertainties in point (mound) locations has been tested by adding random errors to the sampled points. In their test, the added errors (in the $0-100 \mathrm{~m}, 0-300 \mathrm{~m}$ and $0-500 \mathrm{~m}$ ranges) were as high as five to twenty-five times that of the coarsest image resolution used to locate vents. The $0-100 \mathrm{~m}$ errors generate fractal exponent and cut off value identical to those computed for the original dataset. In the case of $0-500 \mathrm{~m}$ random errors, the resulting fractal exponent is $3 \%$ higher than that computed for the original dataset, and the cut offs are very similar to those computed for the original dataset. We performed analyses on clusters exceeding the minimum number of 50 units, thus keeping the error on the scaling parameter smaller than $1 \%$

\section{Results}

Based on the interpretation of the different groups of features, the outputs of fractal analysis were expected to highlight a different involvement of the subsurface below the fields. From the deepest to the shallowest: (i) monogenetic vents are expected to be linked to very deep fluid (magma) reservoirs sitting several tens of kilometers below the surface; (ii) mud volcanoes, scaling the inferred depths of source layers on Earth (Dia, 1999; Fryer et al., 1999; Kopf, 2002; Fryer, 2012) to the lower Martian gravity, are expected to involve a portion of fractured medium that can significantly vary within the first $20 \mathrm{~km}$ of subsurface; (iii) rootless cones are a phenomenon which extends up to the thickness of the inflate lava flows that are estimated to reach a few tens of meters depths (Hiesinger et al., 2007), hence they are not linked to percolating 


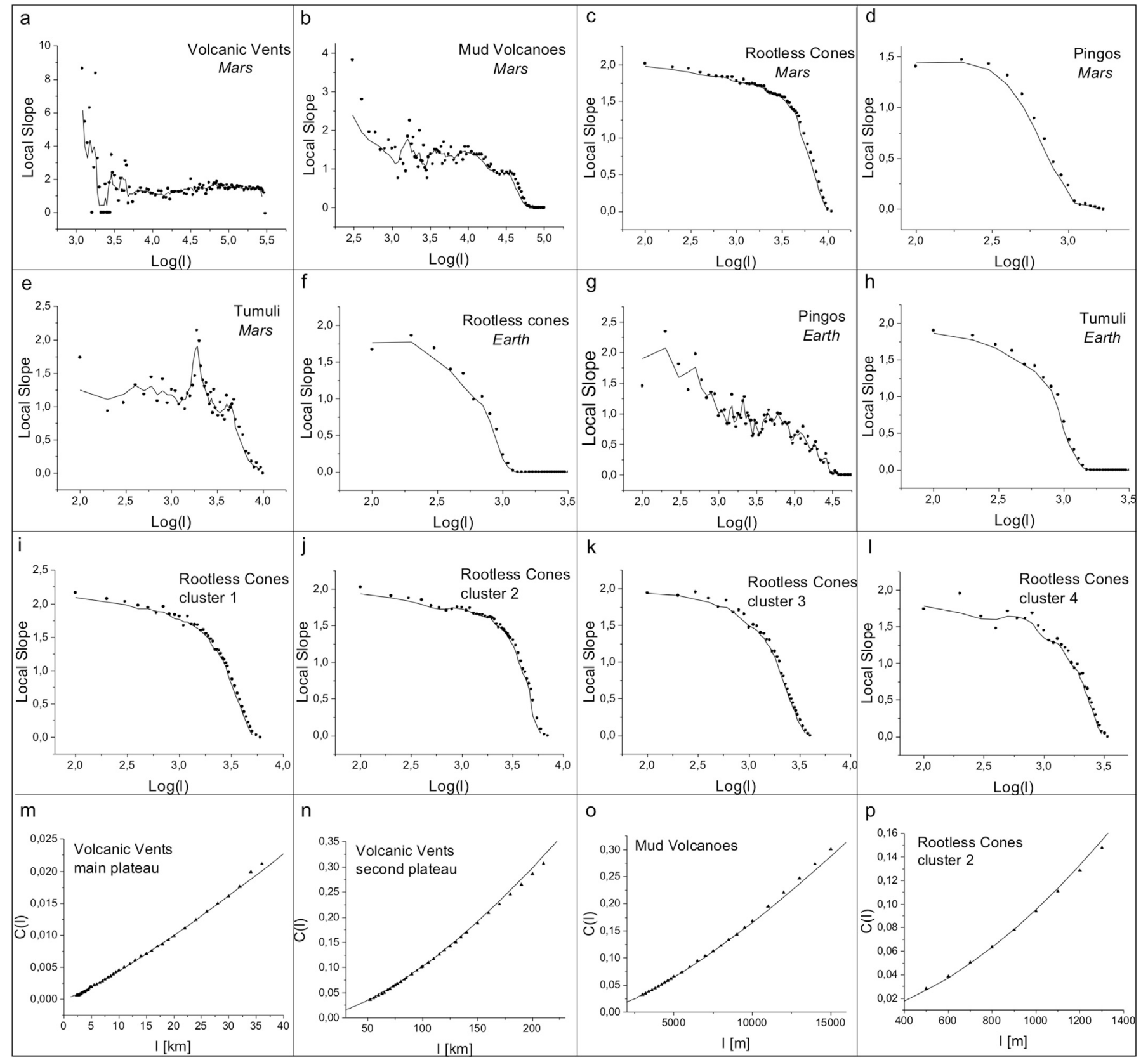

Fig. 5. Size range plots $(a-1)$ and fracture distribution plots $(m-p)$. Size range of interconnected fractures are represented by the plateau stage of the curve where present $(\mathrm{a}, \mathrm{b}, \mathrm{c}, \mathrm{j})$. Where the slope breaks the fractures' distribution stops to be fractal. The corresponding $\log (\mathrm{l})$ value coincides to a specific maximum thickness of the fractured medium that connects the surface to the subsurface (Uco). Graphs from $\mathrm{m}$ to $\mathrm{p}$ show the variation of fractures distribution compared to the Power Law (solid line). Here the goodness of the Uco picking in the previous graph is tested. Fractal distribution follows the Power Law, where data matches the solid line the distribution of fractures/vents is fractal. [1: fractures length; C (1): correlation integral defines the correlation between point at a distance lower to 1; Local Slope: represents the $\Delta \log (\mathrm{C}(1)) / \Delta \log (\mathrm{l})$ ratio].

networks recognizable by means of fractal analysis and it is to be expected a significant chance to have no visible plateau in return; (iv) pingos, that are driven by capillarity processes, are not expected to show any effective plateau in the fractal analysis; (v) tumuli are the result of a pellicular uplift of inflated magma, not even related to effective materials flow-up, thus they are not expected to produce any fractal clustering as well.

Below the results are presented listed for each feature class.

Volcanic vents: the magmatic reservoir is sited up to $32 \pm 4 \mathrm{~km}$ of depth (Uco corresponding to $\log (l)=4.5$ ). Despite the flatten tendency of the data distribution is notably marked within the data describing the first tens of kilometers, a second plateau is also visible and suggests the presence of a deeper reservoir (i.e. a possible two magma chambers feeding). This seems to extend deeper than $200 \pm 22 \mathrm{~km}$ (Uco corresponding to $\log (l)=5.4$ ), however reliability decreases as $\mathrm{R}^{2}$ values drop down (Fig. 5a, m, n).

Mud volcanoes: fractal analysis on the mud volcano cluster showed a clear plateau, noisy close to the Lco but displaying a well recognizable slope break for the Uco; accordingly connected fractures are estimated to reach a depth of $12 \pm 3 \mathrm{~km}$ (Uco corresponding to $\log (l)=4.08$; Fig. $5 \mathrm{~b}$, o).

Rootless cones: in the $\log (C(l))$ v. $\log (l)$ diagram a constant descending trend is displayed (Fig. 5c). No significant plateaus are clearly visible, anyway, due to a weakly flattening tendency between $\log (l)$ values of 3.1 

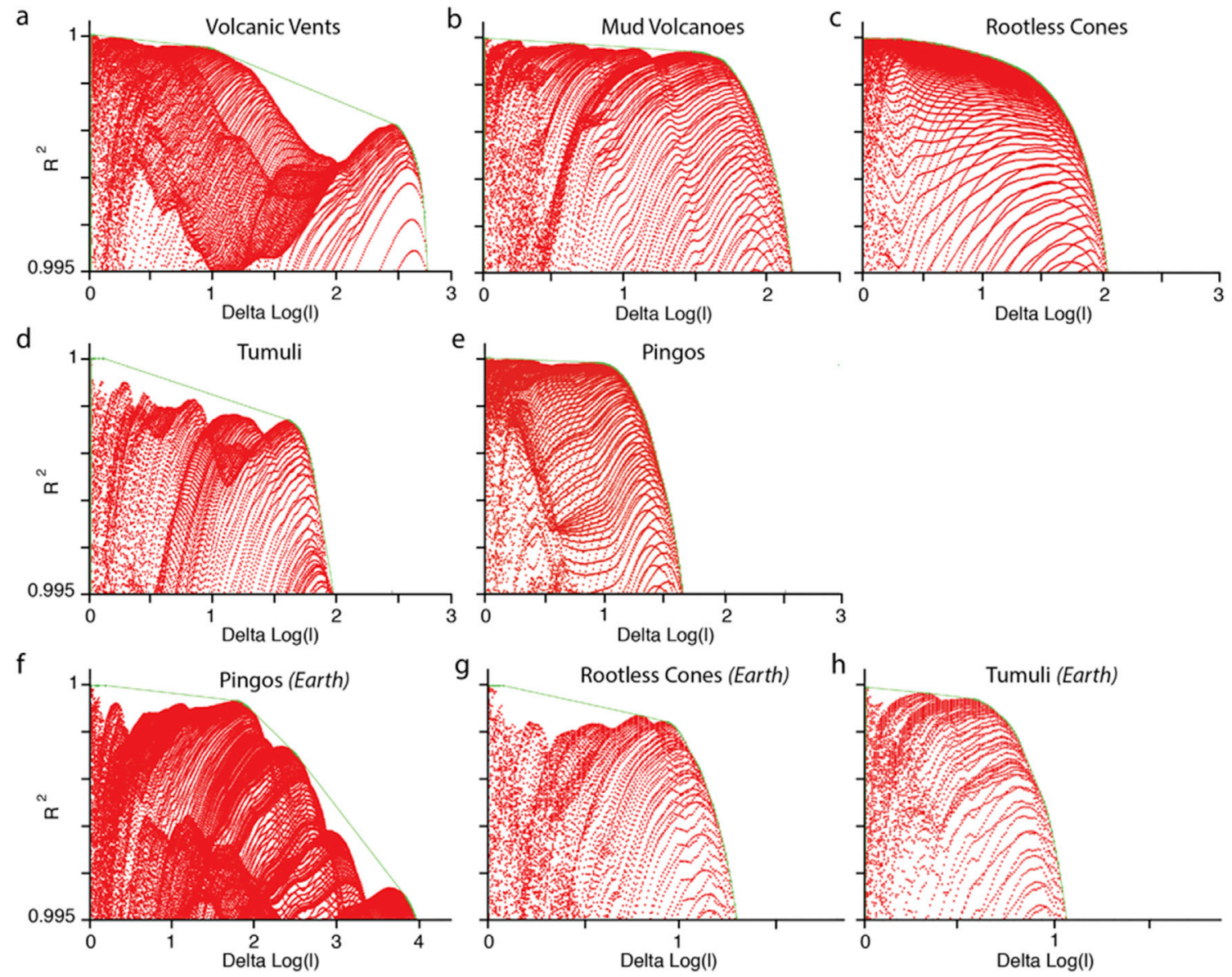

Fig. 6. Plots of all possible $\Delta \log (1)$ and $\mathrm{R}^{2}$ values. The green line is the convex hull the distribution of $\Delta \log (1)-\mathrm{R}^{2}$. The size range is located at the largest value of $\Delta \log (1)$ and $\mathrm{R}^{2}$. Large $\Delta \log (\mathrm{l})$ (possibly $>1$ ) and high $\mathrm{R}^{2}$ values ensure the reliability of the measurements. In figure a) data retrieved from volcanic vents' analysis show double break, the first one with the highest $\mathrm{R}^{2}$ has a remarkably high reliability, the second one has larger uncertainties; b) in the mud volcanoes' case the slope beaks sharply at very high $\mathrm{R}^{2}$ values; c) (rootless cones) no breaks are clearly visible and no size range is detectable; $\mathrm{d}, \mathrm{f}, \mathrm{g}$, $\mathrm{h}$ ) (Martian tumuli; terrestrial pingos, terrestrial rootless cones, terrestrial tumuli) faint break at very low $\Delta \log (\mathrm{l})$ giving very small unreliable size range; e) (pingos) the green line gently declines. Rootless cones, tumuli and pingos do not show any clear size range over with identify a possible fractal distribution. (For interpretation of the references to colour in this figure legend, the reader is referred to the Web version of this article.)

Table 1

Number of units and Uco estimates for each feature group.

\begin{tabular}{lll}
\hline Feature & $\mathrm{n}^{\circ}$ units & Uco $[\mathrm{Km}]$ \\
\hline Mars & & \\
Volcanic vents & 217 & $32 \pm 4 ; 200 \pm 22$ \\
Mud Volcanoes & 174 & $12 \pm 3$ \\
Rootless Cones & 1428 & - \\
- cluster1 RC & 462 & - \\
- cluster2 RC & 566 & $1.2 \pm 0.2$ \\
- cluster3 RC & 281 & - \\
- cluster4 RC & 118 & - \\
Pingos & 281 & - \\
Tumuli & 75 & - \\
Earth & & - \\
Rootless Cones & 65 & - \\
Pingos & 103 & - \\
Tumuli & 105 & \\
\hline
\end{tabular}

and 3.3, we subdivided the features into four sub-clusters in order to identify eventual groups of features with a fractal behavior. The outcomes of these further analyses (Fig. $5 \mathrm{i}-1$ ) displayed no plateau distribution of the data for cluster 1, 3 and 4 and confirmed that no percolating fracture network was active. Differently, cluster 2 showed a slight flattening suggesting a possible relationship with some source located at
$1.2 \pm 0.2 \mathrm{~km}$ depth (Uco corresponding to $\log (l)=3.07$; Fig. $5 \mathrm{p}$ ). On the terrestrial counterpart, the $\log (C(l))$ v. $\log (l)$ diagram shows an abrupt descending trend quickly approaching the zero value, any plateau trend is clearly missing (Fig. 5f).

Pingos \& Tumuli: fractal analysis outputted unequivocal results and we accordingly detected no plateau trend in the data (Fig. $5 \mathrm{~d}$ and e). Hence, as expected for such features associated to different processes such as capillarity, thermo-mechanical and inflating processes, no relationship with percolating fracture network can be inferred from this investigation. Similarly to the rootless cones case discussed above in this section, the fractal analysis outcomes for pingos and tumuli terrestrial analogue sites are clearly missing plateau distributions (Fig. $5 \mathrm{~g}$ and $\mathrm{h}$ ). Indeed, the related diagrams display a sharp abrupt descending trend for tumuli and a noisy but unequivocally descending trend for pingos.

The results we gathered by the application of fractal analysis to the case studies, both on Mars and on Earth, allowed the verification of the geomorphological interpretations of the features of interest. In fact volcanic vent and mud volcano fields showed a relationship with systems of connected fractures, as such structures are supposed to. Martian rootless cones displayed a weak and uncertain possible interplay with shallow fractures, this marking the necessity of better caution while discussing such uncommon features; terrestrial rootless cones, pingos and tumuli instead clearly resulted to have no linkage with any fracture network hydraulically connected to fluid reservoirs at depth. 


\section{Discussion}

The method herein presented is hence a tool that can be profitably used for the interpretation of planetary surfaces and, in the specificity of this work, effective to discriminate mound features on Mars with convergent morphologies but significantly different interplay with the subsurface. In fact, as herein reported, the outcomes of fractal clustering are confirming and validating the major interpretations of the features of interest and, where percolating fracture networks were active, the maximum extension values are well matching with complementary literature data.

Our results point towards various depths for vents consistent with previous works. In fact, volcanic vents of the Tharsis region appear to be linked to reservoirs sited around 30 and $200 \mathrm{~km}$ under the surface reflecting what is to be expected in the magmatic plumbing systems on Mars (e.g. Grott et al., 2013) and what has been observed in the neighboring region of Ascraeus Mons by Pozzobon et al. (2015) where multiple source depths where identified at around 10 and $80 \mathrm{~km}$, drawing a solid relationship between the background data and the fractal outcomes. Similarly, our mud volcano field case shows that the inferred vertical involvement of the crust reaches up a depth where gas hydrate-rich permafrost has been calculated to be theoretically stable and close to the hypothetical water-ice interface $(\sim 15 \mathrm{~km})$ laying beneath the ice table (Clifford et al., 2010). This relationship further matches the mud volcano interpretation by highlighting a connection between landforms that are by definition linked to water and a subsurface location where water, in the form of ice and gas hydrate, is presumed to have been likely sited. Contextually, Martian rootless cones gave back more ambiguous results due to the hard identification of a plateau in the fractal analysis output diagram. In particular three sub-clusters of rootless cones out of four do not show any plateau indicating percolating systems, whereas a slight flattening of the last cluster seems to suggest an uncertain source at a depth of $1.2 \mathrm{~km}$. This on one side leaves doubts about the effective connection with a percolating fracture network and its extension, but at the same time reflects what was expected to happen while applying the technique to features that may be linked to significant, but very shallow conduits. In fact, a fracture extension of $1.2 \mathrm{~km}$ beneath rootless cones appears to be significantly larger with the respect of what could be expected in such case, even considering the lower Martian gravity that allows the placement of thicker lava flows (Hiesinger et al., 2007). It is to be noticed though that, at the field scale where distances between mounds can reach up to tens of kilometers, a resolution quality below the kilometer is hard to pursue and, accordingly, such value could be an overestimation of a shallower process. This uncertainty arises from the very narrow span of the plateau in the Martian rootless cones case study. In fact, while in magmatic and sedimentary volcanism cases the plateaus span over one or more orders of magnitude (Fig. 5), in the rootless cones analysis the flattened tendency is confined between 3.1 and $3.3 \log (l)$ values. Accordingly, such data portion is expressed by a little number of points making the tendency possibly mistakable with background noise (i.e. the noise produced by unavoidable mistakes made during population picking, for instance by mapping several vents fed by the same fracture, which is averagely mitigated by picking a sample of features large enough; refer to the methods section) that is normally present. This result needs thus to be coupled with further information collected on the terrestrial analogue site, where feature interpretation is no question. Hence, for the Icelandic rootless cones case study, the analysis unmistakably underscores the total lack of relationships between such structures and putative underlying percolating fracture systems, remarking the very surficial and nature of the phenomenon unrelated to networks of connected fractures.

Results of fractal analysis of features surely unrelated to percolating systems, such as inflated tumuli and periglacial pingos, unambiguously show a complete lack of any fractal distribution on both planets.

\section{Conclusions}

Our study provides the evidence of the efficiency of the fractal analysis application to infer the extension of percolating fracture networks starting from the distribution of eruption vents. This work validates fractal analysis as a reliable method for mound features discrimination and foster the integration of this investigation technique in future geomorphological observations and within studies intending to probe the entity of the subsurface cracking. Assessing the power of investigation of such methodology, we encourage to take it into consideration within the exploration process frame since it provides insights regardless of the usual physical limits that surveying the subsurface presents. Due to the freshness of this kind of natural systems investigation, many phenomena can be explored when percolating cracking is presumed or assessed. This allows features discrimination and fracturing mechanism deeper understanding both in the frame of already known contexts, like terrestrial environments, and on extra-terrestrial planetary landscapes, where cracking behavior at all scales can be widely different from Earth's ones, poorly understood and still limited by the surveying efficiency of today space exploration techniques.

\section{Author disclosure statement}

No competing financial interests exist.

\section{Acknowledgments}

We thank the reviewers who provided helpful and detailed suggestions to improve the manuscript. This work has been supported by the Italian Space Agency (ASI) (ASI-INAF agreement no.2017-03-17).

\section{References}

Balme, M.R., Gallagher, C., 2009. An equatorial periglacial landscape on Mars. Earth Planet Sci. Lett. 285, 1-15. https://doi.org/10.1016/j.epsl.2009.05.031.

Bleacher, J.E., Greeley, R., Williams, D.A., Cave, S.R., Neukum, G., 2007a. Trends in effusive style at the Tharsis Montes, Mars, and implications for the develop- ment of the Tharsis province. J. Geophys. Res. 112, E09005. https://doi.org/10.1029/ 2006JE002873.

Bleacher, J.E., Glaze, L.S., Greeley, R., Hauber, E., Baloga, S.M., Sakimoto, S.E.H., Williams, D.A., Glotch, T.D., 2009. Spatial and alignment analyses for a fi eld of small volcanic vents south of Pavonis Mons and implications for the Tharsis province. J. Volcanol. Geoth. Res. 185, 96-102. https://doi.org/10.1016/j.jvolgeores.2009.04. 008.

Bonini, M., Mazzarini, F., 2010. Mud volcanoes as potential indicators of regional stress and pressurized layer depth. Tectonophysics 494, 32-47. https://doi.org/10.1016/j. tecto.2010.08.006.

Bonnet, E., Bour, O., Odling, N.E., Davy, P., Main, I., Cowie, P., Berkowitz, B., 2001. Scaling of fracture system in geological media. Rev. Geophys. 39, 347-383.

Bruno, B.C., Fagents, S.A., Hamilton, C.W., Burr, D.M., Baloga, S.M., 2006. Identification of volcanic rootless cones, ice mounds, and impact craters on Earth and Mars: using spatial distribution as a remote sensing tool. J. Geophys. Res. E Planets 111, 1-16. https://doi.org/10.1029/2005JE002510.

Bruno, B.C., Fagents, S.A., Thordarson, T., Baloga, S.M., Pilger, E., 2004. Clustering within rootless cone groups on Iceland and Mars: effect of nonrandom processes. J. Geophys. Res. E Planets 109, 1-11. https://doi.org/10.1029/2004JE002273.

Burr, D.M., Tanaka, K.L., Yoshikawa, K., 2009. Pingos on Earth and Mars. Planet. Space Sci. 57, 541-555. https://doi.org/10.1016/j.pss.2008.11.003.

Carr, M.H., 2006. The Surface of Mars, Cambridge Planetary Science Series. https://doi. org/10.1086/518077.

Clauset, A., Rohilla Shalizi, C.J., Newman, M.E., 2009. Power-law distributions in empirical data. SIAM Rev. 51, 661-703. https://doi.org/10.1214/13-AOAS710.

Clifford, S.M., Lasue, J., Heggy, E., Boisson, J., McGovern, P., Max, M.D., 2010. Depth of the Martian cryosphere: revised estimates and implications for the existence and detection of subpermafrost groundwater. J. Geophys. Res. 115, E07001. https:// doi.org/10.1029/2009JE003462.

Connor, C.B., Conway, F.M., 2000. Basaltic volcanic fields. In: Sigurdsson, H. (Ed.), Encyclopedia of Volca- Noes. Academic Press, New York, pp. 331-343.

Darcel, C., Bour, O., Davy, P., de Dreuzy, J.R., 2003. Connectivity properties of twodimensional fracture networks with stochastic fractal correlation. Water Resour. Res. 39, 1272. https://doi.org/10.1029/2002WR001628.

Dia, A., 1999. Trinidad mud volcanoes: where do the expelled fluids come from? Geochem. Cosmochim. Acta 63, 1023-1038. https://doi.org/10.1016/S00167037(98)00309-3. 
Dimitrov, L., 2002. Mud volcanoes - the most important pathways for degassing deeply buried sediments. Earth Sci. Rev. 59, 49-76. https://doi.org/10.1016/S0012 8252(02)00069-7.

Dundas, C.M., McEwen, A.S., 2010. An assessment of evidence for pingos on Mars using HiRISE. Icarus 205, 244-258. https://doi.org/10.1016/j.icarus.2009.02.020.

Fryer, P., 2012. Serpentinite mud volcanism: observations, processes, and implications. Ann. Rev. Mar. Sci. 4, 345-373. https://doi.org/10.1146/annurev-marine-120710100922.

Fryer, P., Wheat, C.G., Mottl, M.J., 1999. Mariana blueschist mud volcanism: implications for conditions within the subduction zone. Geol. 27, 103-106. https://doi.org/10. 1130/0091-7613(1999)027.

Giacomini, L., Massironi, M., Martellato, E., Frigeri, A., Cremonese, G., 2009. Inflated flows on Daedalia Planum ( Mars )? Clues from a comparative analysis with the Payen volcanic complex ( Argentina ). Planet. Space Sci. 57, 556-570. https://doi.org/10. 1016/j.pss.2008.12.001

Giacomini, L., Massironi, M., 2010. Tumuli and pingos: a comparative analysis between Daedalia Planum and elysium Planitia mounds. European Planetary Siecnce Congress $5,414$.

Grosse, G., Jones, B.M., 2011. Spatial distribution of pingos in northern Asia. Cryosphere 5, 13-33. https://doi.org/10.5194/tc-5-13-2011.

Grott, M., Baratoux, D., Hauber, E., Sautter, V., Mustard, J., Gasnault, O., Ruff, S.W., Karato, S.I., Debaille, V., Knapmeyer, M., Sohl, F., Van Hoolst, T., Breuer, D., Morschhauser, A., Toplis, M.J., 2013. Long-term evolution of the martian crustmantle system. Space Sci. Rev. 174, 49-111. https://doi.org/10.1007/s11214-0129948-3.

Hamilton, C.W., Thordarson, T., Fagents, S.A., 2010. Explosive lava-water interactions I: architecture and emplacement chronology of volcanic rootless cone groups in the 1783-1784 Laki lava flow. Iceland. Bull. Volcanol 72, 449-467. https://doi.org/10. 1007/s00445-009-0330-6.

Hargitai, H., Kereszturi, A. (Eds.), 2015. Encyclopedia of Planetary Landforms. SpringerScience, New York. https://doi.org/10.1007/978-1-4614-3134-3.

Hiesinger, H., Head, I.W., Neukum, G., 2007. Young lava flows on the eastern flank of ascaraeus Mons: rheological properties derived from high resolution stereo camera(HRSC) images and Mars orbiter laser Altimeter(MOLA) data. J. Geophys. Res. E Planets 112. https://doi.org/10.1029/2006JE002717.

Hon, K., Kauahikaua, J., Denlinger, R., Mackay, K., 1994. Emplacement and inflation of pahoehoe sheet flows; observations and measurements of active lava flows on Kilauea Volcano. Hawaii. GSA Bull. 106, 351-370.

Kopf, A.J., 2002. Significance of mud volcanism. Rev. Geophys. 40, 1005. https://doi. org/10.1029/2000RG000093.

Keszthelyi, L., Self, S., 1998. Some physical requirements for the emplacement of long basaltic lava flows. J. Geophys. Res., 103464 https://doi.org/10.1029/98JB00606, 447-27.

Lanagan, P.D., McEwen, A.S., Keszthelyi, L.P., Thordarson, T., 2001. Rootless cones on Mars indicating the presence of shallow equatorial ground ice in recent times. Geophys. Res. Lett. 28, 2365-2367. https://doi.org/10.1029/2001GL012932.

Le Corvec, N., Sporli, K.B., Rowland, J., Lindsay, J., 2013. Spatial distribution and alignments of volcanic centers: clues to the formation of monogenetic volcanic fields Earth Sci. Rev. 124, 96-114. https://doi.org/10.1016/j.earscirev.2013.05.005.

Lucchetti, A., Pozzobon, R., Mazzarini, F., Cremonese, G., Massironi, M., 2017. Brittle ice shell thickness of Enceladus from fracture distribution analysis. Icarus 297, 252-264. https://doi.org/10.1016/j.icarus.2017.07.009.

Malin, M.C., Bell III, J.F., Cantor, B.A., Caplinger, M.A., Calvin, W.M., Clancy, R.T., Edgett, K.S., Edwards, L., Haberle, R.M., James, P.B., 2007. Context Camera investigation on board the Mars reconnaissance orbiter. J. Geophys. Res. 112 E05S04 doi: $10.1029 / 2006 J E 002808$.

Mandelbrot, B.B., 1982. The Fractal Geometry of Nature. Freeman, San Francisco, 468 p.

Mattsson, H.B., Hoskuldsson, A., 2005. Eruption reconstruction, formation of flow-lobe tumuli and eruption duration in the 5900 BP Helgafell lava field (Heimaey), south Iceland. J. Volcanol. Geoth. Res. 147 (1-2), 157-172.

Mazzarini, F., 2004. Volcanic vent self-similar clustering and crustal thickness in the northern Main Ethiopian Rift. Geophys. Res. Lett. 31, 1-4. https://doi.org/10.1029/ 2003 GL018574.

Mazzarini, F., Keir, D., Isola, I., 2013. Spatial relationship between earthquakes and volcanic vents in the central-northern Main Ethiopian Rift. J. Volcanol. Geoth. Res. 262, 123-133.

Mazzarini, F., Isola, I., 2010. Monogenetic vent self-similar clustering in extending continental crust: examples from the East African Rift System. Geosphere 6, 567-582. https://doi.org/10.1130/GES00569.1.

Mazzarini, F., Isola, I., 2007. Hydraulic connection and fluid overpressure in upper crustal rocks: evidence from the geometry and spatial distribution of veins at Botrona quarry, southern Tuscany. Italy. J. Struct. Geol. 29, 1386-1399. https://doi.org/10.1016/j. jsg.2007.02.016.

Mazzarini, F., 2007. Vent distribution and crustal thickness in stretched continental crust: the case of the Afar Depression (Ethiopia). Geosphere 3, 152-162. https://doi.org/ 10.1130/GES00070.1.

Mazzini, A., Etiope, G., 2017. Mud volcanism: an updated review. Earth Sci. Rev. 168, 81-112. https://doi.org/10.1016/j.earscirev.2017.03.001.

McEwen, A.S., Eliason, E.M., Bergstrom, J.W., Bridges, N.T., Hansen, C.J., Delamere, W.A., Grant, J.A., Gulick, V.C., Herkenhoff, K.E., Keszthelyi, L., Kirk, R.L., Mellon, M.T., Squyres, S.W., Thomas, N., Weitz, C.M., 2007. Mars reconnaissance Orbiter's high resolution imaging science experiment (HiRISE). J. Geophys. Res. 112, E05S02 doi: 10 .1029/2005JE002605.

Németh, K., Haller, M.J., Martin, U., Risso, C., Massaferro, G., 2008. Morphology of lava tumuli from Mendoza (Argentina), patagonia (Argentina), and Al-Haruj (Libya). Z. Geomorphol. 52, 181-194. https://doi.org/10.1127/0372-8854/2008/0052-0181.

Németh, K., 2010. Monogenetic volcanic fields: origin, sedimentary record, and relationship with polygenetic volcanism. GSA (Geol. Soc. Am.) Spec. Pap. (Reg. Stud.) 470, 43-66.

Németh, K., Kereszturi, G., 2015. Monogenetic volcanism: personal views and discussion. Int. J. Earth Sci. 104 (8), 2131-2146.

Nemeth, K., Wu, J., Sun, C., Liu, J., 2017. Update on the volcanic geoheritage values of the pliocene to quaternary arxan-chaihe volcanic field, inner Mongolia, China. Geoheritage 9 (3), 279-297.

Noguchi, R., Höskuldsson, Á., Kurita, K., 2016. Detailed topographical, distributional, and material analyses of rootless cones in Myvatn. Iceland. J. Volcanol. Geotherm. Res. 318, 89-102. https://doi.org/10.1016/j.jvolgeores.2016.03.020.

Oehler, D.Z., Allen, C.C., 2010. Evidence for pervasive mud volcanism in Acidalia Planitia, Mars. Icarus 208, 636-657. https://doi.org/10.1016/j.icarus.2010.03.031.

Oehler, D.Z., Allen, C.C., 2012. Giant polygons and mounds in the lowlands of Mars: signatures of an ancient ocean? Astrobiology 12, 601-615. https://doi.org/10.1089/ ast.2011.0803.

Oehler, D.Z., Etiope, G., 2017. Methane seepage on Mars: where to look and why. Astrobiology 17 ast.2017.1657. https://doi.org/10.1089/ast.2017.1657.

Ollier, C.D., 1964. Tumuli and lava blisters of Victoria, Australia. Nature 202, 1284.

Page, D.P., Murray, J.B., 2006. Stratigraphical and morphological evidence for pingo genesis in the Cerberus plains. Icarus 183, 46-54. https://doi.org/10.1016/j.icarus. 2006.01.017.

Pozzobon, R., Mazzarini, F., Massironi, M., Marinangeli, L., 2015. Self-similar clustering distribution of structural features on Ascraeus Mons (Mars): implications for magma chamber depth. Geol. Soc. London, Spec. Publ. 401 (1), 203-218. https://doi.org/10. 1144/SP401.12.

Prieto-Ballesteros, O., Kargel, J.S., Fairén, A.G., Fernández-Remolar, D.C., Dohm, J.M., Amils, R., 2006. Interglacial clathrate destabilization on Mars: possible contributing source of its atmospheric methane. Geol. 34, 149. https://doi.org/10.1130/G22311. 1 .

Renshaw, C.E., 1999. Connectivity of joint networks with power law length distributions. Water Resour. Res. 35, 2661-2670.

Rossi, M.J., Gudmundsson, A., 1996. The morphology and formation of flow-lobe tumuli on Icelandic shield volcanoes. J. Volcanol. Geoth. Res. 72, 291-308.

Sheth, H., Mathew, G., Pande, K., Mallick, S., Jena, B., 2004. Cones and crater on Mount Pavagadh, Deccan traps: rootles cones? Proc. Indian Acad. Sci. (Earth Planet. Sci.) 113, 831-838.

Skinner, J.A., Tanaka, K.L., 2007. Evidence for and implications of sedimentary diapirism and mud volcanism in the southern Utopia highland-lowland boundary plain. Mars. Icarus 186, 41-59. https://doi.org/10.1016/j.icarus.2006.08.013.

Skinner, J. a., Mazzini, A., 2009. Martian mud volcanism: terrestrial analogs and implications for formational scenarios. Mar. Petrol. Geol. 26, 1866-1878. https://doi. org $/ 10.1016 /$ j.marpetgeo.2009.02.006.

Smith, I.E.M., Németh, K., 2017. In: Németh, K., Carrasco-Nuñez, G., Aranda-Gomez, J.J., Smith, I.E.M. (Eds.), Source to Surface Model of Monogenetic Volcanism: a Critical Review Monogenetic Volcanism. The Geological Society Publishing House, Bath, UK, p. 446.

Thorarinsson, S., 1953. The crater groups in Iceland. Bull. Volcanol. 14, 3-44.

van Loon, A., 2010. Sedimentary Volcanoes: Overview and Implications for the Definition of a Volcano on Earth. https://doi.org/10.1130/2010.2470(03), 80301.

Walker, G.P.L., 1991. Structure, and origin by injection of lava under surface crust, of tumuli, lava rises, lava-rise pits, and lava-inflation clefts in Hawaii. Bull. Volcanol. 53 (7), 546-558.

Walsh, J.J., Watterson, J., 1993. Fractal analysis of fracture pattern using the standard box-counting tech- nique: valid and invalid methodologies. J. Struct. Geol. 15, 1509-1512. https://doi.org/10.1016/0191-8141(93)90010-8. 